\title{
A method to establish a mouse model of bone marrow microenvironment injury
}

\author{
Wenzhe $\mathrm{CHENG}^{1)}$, Quanhu GE ${ }^{1)}$, Longfei WAN ${ }^{1)}$, Xiaoyi WANG ${ }^{1)}$, \\ Xueling $\mathrm{CHEN}^{2}$, and Xiangwei WU ${ }^{1,3)}$ \\ 1) Department of General Surgery, First Affiliated Hospital, School of Medicine, Shihezi University, Shihezi, Xinjiang \\ 832008, P.R. China \\ ${ }^{2)}$ Department of Immunology, School of Medicine, Shihezi University, Shihezi, Xinjiang 832002, P.R. China \\ ${ }^{3)}$ Laboratory of Translational Medicine, School of Medicine, Shihezi University, Shihezi, Xinjiang 832008, P.R. \\ China
}

\begin{abstract}
A normal bone marrow microenvironment plays a very important role in the normal functioning of hematopoietic stem cells. Once disturbed, this microenvironment can become favorable for the occurrence of blood disorders, cancers, and other diseases. Therefore, further studies on the bone marrow microenvironment should be performed to reveal regulatory and stem cell fate determination mechanisms and promote the development of bone marrow transplantation, tissue repair and regenerative medicine, and other fields. A small animal model for further research is also urgently needed. In this study, an electric shock device was designed to elicit a femur bone marrow microenvironment injury in mice. A wire was inserted into the distal femur but not into the proximal femur, and the bone marrow microenvironment was evidently damaged by application of $100 \pm 10 \mathrm{~V}$ for $1.5 \pm 0.5 \mathrm{~min}$; mortality, however, was low in the mice. Gross observation, hematoxylin and eosin staining, immunohistochemistry, bright-field microscopy, and micro-CT scanning were also conducted. A large number of new blood capillaries and sinusoids appeared in the injured distal femur after 2 weeks. The capillaries in the injured femur disappeared after 4 weeks, and mature blood vessels were scattered throughout the injured area. Red blood cells disappeared, and the cellular structure and trabecular bone were better than those observed 2 weeks previously. Thus, we developed a simply operated, accurate, reliable, and easily controlled small animal model as a good technical platform to examine angiogenesis and segmentation damage in the bone marrow microenvironment. Key words: bone marrow microenvironment, electric shock, micro-CT, small animal model
\end{abstract}

\section{Introduction}

The bone marrow microenvironment, through multiple hematopoietic cell components [10], non-hematopoietic cells, extracellular matrix, and other signaling proteins [23], is the basis for hematopoietic stem cell survival. This microenvironment supports hematopoietic stem cell resting, [11, 30],renewal [2], differentiation, migration
$[9,16]$, mobilization, and homing [17]. A normal bone marrow microenvironment also plays a very important role in the normal functioning of hematopoietic stem cells; once disturbed, this microenvironment can cause blood disorders, cancers, and other diseases [3, 6, 12, $18,22,24]$. Therefore, further studies on the bone marrow microenvironment should be conducted to reveal regulatory and stem cell fate determination mechanisms

(Received 14 December 2016 / Accepted 18 May 2017 / Published online in J-STAGE 13 June 2017)

Addresses corresponding: X. Wu, Department of General Surgery, First Affiliated Hospital, School of Medicine, Shihezi University, Shihezi, Xinjiang 832008, P.R. China

X. Chen, Department of Immunology, School of Medicine, Shihezi University, Shihezi, Xinjiang 832002, P.R. China

(C)2017 Japanese Association for Laboratory Animal Science 
and promote the development of bone marrow transplantation, tissue repair, and regenerative medicine, and other fields. Further research is also urgently needed because the exact mechanism remains unknown and clinical treatment effects are very poor.

Electric shock injury is usually induced by using an electric shock device that converts electrical energy into heat energy and thus causes damage to animals[14, 21], According to the Joule-Lenz law, $\mathrm{Q}=\mathrm{I}^{2} \mathrm{RT}$, where the voltage and resistance of the body are constant and the degree of damage to an animal's body is directly proportional to the electric current density and the electric current density of the unit volume. The actual damage of the current via electric shock injury can be divided into local and systemic effects. Lee and Astumian proposed two mechanisms of local damage: (1) thermal damage of heat in Joules in the current path and (2) the direct destructive effect of the current via the electrode structure $[1,15]$, The current through the body can change the balance of ions in cells, produce electrophoresis, induce an electro-osmosis reaction, and alter cell morphology [5, 7, 25-27]. Thus, the heart, skeletal muscle, brain, bone, and other tissues exhibit various pathological changes $[8,19,28,29]$. Different electric shock injury models are often established by clinical experts in forensic science and commonly used to examine high-voltage electric shock causing limb and secondary tissue damage in other areas and provide a reliable basis for forensic identification. However, the voltage is often too high and difficult to control in these models. The body is seriously damaged, and necrosis and high mortality rates are observed. Animal models used to evaluate the changes in blood vessels, serum, and other parts of rats, rabbits, and other large animals do not induce low-voltage damage in the femur of mice but eventually damage the bone marrow microenvironment.

Some animal models have been established in previous studies on electrical injury models $[4,13,20]$. However, the voltage used in these animal models was very high, usually exceeding $10,000 \mathrm{~V}$, which induced excessive damage in the body and a mortality rate over $80 \%$. Therefore, these animal models are unsuitable for bone marrow microenvironment injury modeling. Hence, an optimum animal model should be established to investigate the bone marrow microenvironment. In this study, a self-made electric shock device was used to drill into the knee of the hind femur in mice to damage the bone marrow microenvironment and establish a mouse bone marrow microenvironment injury model. The mice were sacrificed after 2 or 4 weeks, and the damaged femur was removed. Gross observation, hematoxylin and eosin staining, immunohistochemistry, bright-field microscopy, and micro-CT scanning were conducted to observe the bone marrow microenvironment and assess the feasibility of the model, which could provide a good experimental platform in the clinical search for reasonable and effective treatments.

\section{Materials and Methods}

\section{Mice}

Experimental procedures were performed in accordance with the Guidelines for the Care and Use of Laboratory Animals of Shihezi University. The protocol was approved by the Committee on the Ethics of Animal Experiments of the Shihezi University. Twelve-week-old $\mathrm{BALB} / \mathrm{C}$ (male or female, a total of 555) mice were obtained from Xinjiang Medicine University Medical Laboratory Animal Center and were housed in a room under the following conditons: $22-25^{\circ} \mathrm{C}, 50-60 \%$ relative humidity, and a $12 \mathrm{~h} / 12 \mathrm{~h}$ light/dark cycle. The mice were provided free access to food and water. In the experiment, the mice were anesthetized with sodium pentobarbital $(40 \mathrm{mg} / \mathrm{kg}$, intraperitoneal), treated aseptically throughout the experiments, and sacrificed through decapitation. After the electric shock was administered (15 mice were used for each setting of the injury model), the injured femur was collected from the mice to observe the injury in the bone marrow microenvironment. All efforts were made to minimize suffering.

\section{Self-made electric shock device (Fig. 1)}

A voltage regulator was connected to a $220 \mathrm{~V}$ AC power supply to ensure that the output voltage was maintained at $220 \mathrm{~V}$. A contactor was connected in series with a time relay to open or close the power supply within a set time. An adjustable transformer in series with the time relay was used to increase or decrease the voltage at both ends of the femur to satisfy the test requirements. This study mainly aimed to reduce the voltage, reduce the damage to the surrounding tissue, and ensure operator safety. A sliding rheostat was used that could be adjusted to change the current through the femur. A voltmeter was placed parallel to the femur, an ammeter was set in a series with the femur, and the resistance 
between the two metallic lines was estimated by reading the voltmeter and the ammeter. The distance between the two metallic lines was adjusted to reduce the experimental error and ensure that the resistance between the two metallic lines was constant. After numerous experiments were performed, the distance between the two metallic lines was approximately $2 \mathrm{~cm}$. Therefore, experimental results could be achieved by changing the voltage and time variables.

\section{Bone marrow microenvironment injury model}

The mice were intraperitoneally injected with sodium pentobarbital (40 mg/kg, intraperitoneal) anesthesia and placed on a sterile stage. Their limbs were fixed after they entered the state of anesthesia. The right hind knee joint surgical area was disinfected by using $2 \%$ povidone-iodine, their skin and muscle were cut with sterile ophthalmic scissors, the patella was pushed aside, and the femoral articular surface was exposed. Knee flexion

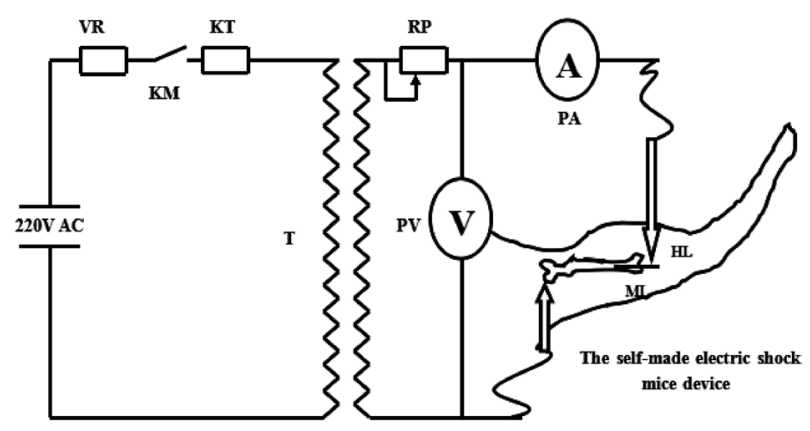

Fig. 1. The self-made electric shock device for mice. VR: Voltage regulator, KM: Contactor, KT: Time relay, T: Adjustable transformer, RP: Slide rheostat, PA: Ammeter, PV: Voltmeter, ML: Metallic line, HL: Hind leg.

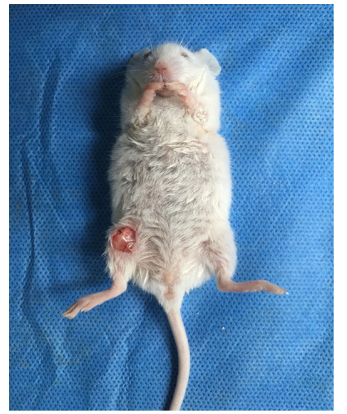

A Incision

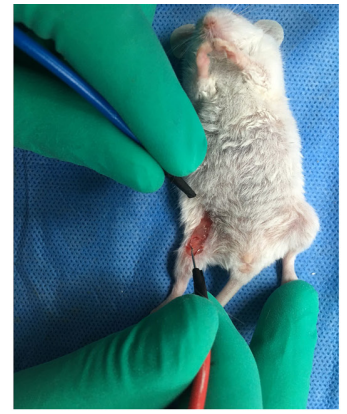

B Electric shock

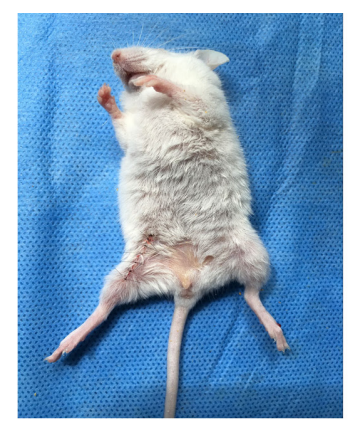

C was performed to secure the mouse femur, and the operating platform was maintained vertically. Subsequently, a $1 \mathrm{ml}$ syringe needle was used to drill holes in the center of the femoral articular surface parallel to the femur at a depth of 3-5 mm. An iron-nickel-chromium alloy wire with a length of $1.5 \mathrm{~cm}$ and a diameter of about $0.27 \mathrm{~mm}$ was gently placed into the hole at a depth of about $6 \mathrm{~mm}$. One end of the electrode was in contact with the exposed part of the metal wire, and the other end was placed in the proximal portion of the same femur. The distance between the two electrodes was $2 \mathrm{~cm}$. The power switch was turned on to cause bone marrow microenvironment damage. The bilateral femur was immersed in a fixative, and gross observation, H\&E staining, immunohistochemistry, bright-field microscopy, and micro-CT scanning were performed to obtain the minimum voltage and time that induced bone marrow microenvironment damage. The femur was handled according to the parameters of the electric shock. Physiological saline was used to wash the drilling area, and the knee joint was closed layer by layer. Post-operatively, the mice were injected with $50 \mathrm{mg} / \mathrm{kg}$ penicillin sodium once a day for 5 days to prevent infection (Fig. 2). After 2 or 4 weeks, the bilateral femur was collected to observe the recovery of the bone marrow microenvironment.

\section{Histopathological processing}

The samples were soaked in a fixative consisting of $10 \%$ neutral formalin, phosphate buffer, and other components for 4 days. Subsequently, the samples were soaked for $6 \mathrm{~h}$ in a decalcification solution formulated with the following proportions: $7 \mathrm{~g}$ of alumina, $5 \mathrm{ml}$ of acid, $8.5 \mathrm{ml}$ of hydrochloric acid, and $100 \mathrm{ml}$ of single-

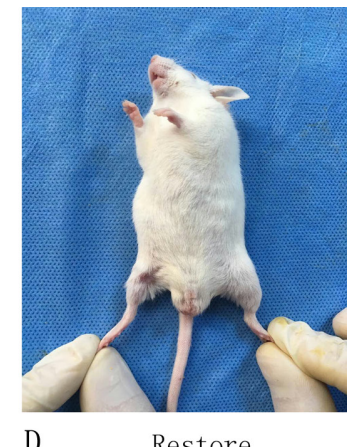

Restore

Fig. 2. The recovery of the wound surface. (A) An incision was made in the knee joint in 0 week. (B) An electric shock was applied to the femur at the knee joint at 0 week. (C) The knee joint was sutured at 0 week. (D) The incision of the knee joint exhibited good recovery after 4 weeks. 
distilled water. Longitudinally oriented sections of $4-\mu \mathrm{m}$ thick bone, including the metaphysis and the diaphysis, were processed for H\&E staining and immunohistochemical staining performed on CD34 expressed in the bone marrow microenvironment.

\section{Immunohistochemistry}

Sections of each specimen were prepared on glass slides and baked at $65^{\circ} \mathrm{C}$ for $2 \mathrm{~h}$. Paraffin was removed from the tissue sections through three consecutive treatments with xylene and rehydrated through sequential immersion in graded alcohol. After the paraffin was removed, the sections were incubated in methanol hydrogen peroxide (3\%) for $10 \mathrm{~min}$ to eliminate endogenous peroxidase and were subsequently washed with tap water. Antigens were retrieved by heating the samples in a microwave oven at high power for approximately 8 $\mathrm{min}$ in a citrate buffer solution and cooled for 30-40 min at room temperature. The slides were washed three times in phosphate-buffered saline (PBS) and incubated with anti-CD34 antibody (ab81289, Abcam, Cambridge, MA, USA dilution 1:200). Each section was incubated with $40 \mu \mathrm{l}$ of the diluted antibody at $4^{\circ} \mathrm{C}$ overnight, whereas negative control sections were incubated with PBS. The slides were warmed at room temperature for $20 \mathrm{~min}$, washed three times in PBS, and incubated with $40 \mu 1$ of secondary antibody for $30 \mathrm{~min}$ at $37^{\circ} \mathrm{C}$. The sections were washed again with PBS, treated with fresh diaminobenzidine solution, lightly stained with hematoxylin to highlight the cell nuclei, and dehydrated with graded alcohol and xylene. An anti-fade mounting medium (ZSGB-Bio, Beijing, China) and glass cover slips were then added. The slides were stored at room temperature until analysis. CD34 is a marker of vascular endothelial cells, and the positive expression areas are brown.

\section{Micro-CT angiography}

Blood vessels in the bone were analyzed through the angiography of Microfil-perfused long bones. After the mice were sacrificed, the thoracic cavity was opened, the liver was resected, and the inferior vena cava was severed. The vasculature was flushed with $0.9 \%$ normal saline solution containing heparin sodium $(100 \mathrm{U} / \mathrm{ml})$ through a needle inserted into the left ventricle. The specimens were pressure-fixed with $10 \%$ neutral buffered formalin. Formalin was flushed from the vessels by using heparinized saline solution, and the vasculature was injected with a radiopaque silicone rubber containing

\begin{tabular}{|l|l|l|l|l|l|}
\hline $\mathbf{v}$ & $\mathbf{0 . 5 m i n}$ & $\mathbf{1 . 0 m i n}$ & \multicolumn{1}{|c|}{$1.5 \mathrm{~min}$} & $\mathbf{2 . 0 m i n}$ & $\mathbf{2 . 5 m i n}$ \\
\hline $10 \mathrm{v}$ & A-P-0 & A-P-0 & A-P-0 & A-P-0 & A-P-0 \\
\hline $\mathbf{3 0 v}$ & A-P-0 & A-P-0 & A-P-0 & A-P-0 & A-P-0 \\
\hline $\mathbf{5 0 v}$ & A-P-0 & A-P-0 & A-P-0 & A-P-0 & A-P-0 \\
\hline $70 v$ & A-P-0 & A-P-0 & A-P-0 & B-P-0.067 & B-P-0.133 \\
\hline 90v & A-P-0 & B-P-0 & B-P-0 & B-P-0 & B-P-0.067 \\
\hline 110v & B-P-0 & B-P-0 & B-P-0 & B-P-0.067 & B-P-0.267 \\
\hline 130v & B-P-0.200 & B-P-0.133 & B-P-0.200 & B-P-0.267 & B-P-0.333 \\
T: Time V: Voltage A: No Damage B: Damage P: Mortality rate
\end{tabular}

Fig. 3. Electric shock conditions setting and results. At $100 \pm 10$ $\mathrm{V}$ for $1.5 \pm 0.5 \mathrm{~min}$, the bone marrow microenvironment was evidently damaged, and mortality was low in the mice.

lead chromate (Microfil MV-122, Flow Tech). The samples were stored at $4{ }^{\circ} \mathrm{C}$ overnight for contrast agent polymerization. The femurs were dissected from the specimens and soaked for 4 days in 10\% neutral buffered formalin to ensure complete tissue fixation. The specimens were subsequently treated for $6 \mathrm{~h}$ with a decalcification solution formulated as follows to decalcify the bone and facilitate image thresholding of the femoral vasculature from the surrounding tissues: $7 \mathrm{~g}$ alumina: $5 \mathrm{ml}$ acid: $8.5 \mathrm{ml}$ hydrochloric acid: $100 \mathrm{ml}$ single-distilled water. Images were obtained using a high-resolution $(9-\mu \mathrm{m}$ isotropic voxel size) micro-CT imaging system (CTvol).

\section{Statistical analysis}

Data are presented as the mean \pm SEM and were analyzed using a one-way ANOVA followed by Dunnett's test.

\section{Results}

\section{Optimum shock parameters}

At $100 \pm 10 \mathrm{~V}$ for $1.5 \pm 0.5 \mathrm{~min}$, the bone marrow microenvironment was evidently damaged, and mortality was low in the mice (Fig. 3).

\section{Gross observation}

The specimens were soaked in the tissue fixative for 4 days, and the changes were observed and compared with the normal femur (Fig. 4). At 0 week, the marrow cavity of the electrically shocked mice showed hemorrhage, and a large black necrotic area appeared. The area 
of the bone marrow cavity affected by hemorrhage and necrosis was significantly decreased at 2 weeks. At 4 weeks, the marrow cavity of the electrically shocked mice exhibited good recovery, and the gross appearance of the bone marrow cavity was better than 2 weeks previously. The injured distal femur was significantly changed 2 and 4 weeks after injury.

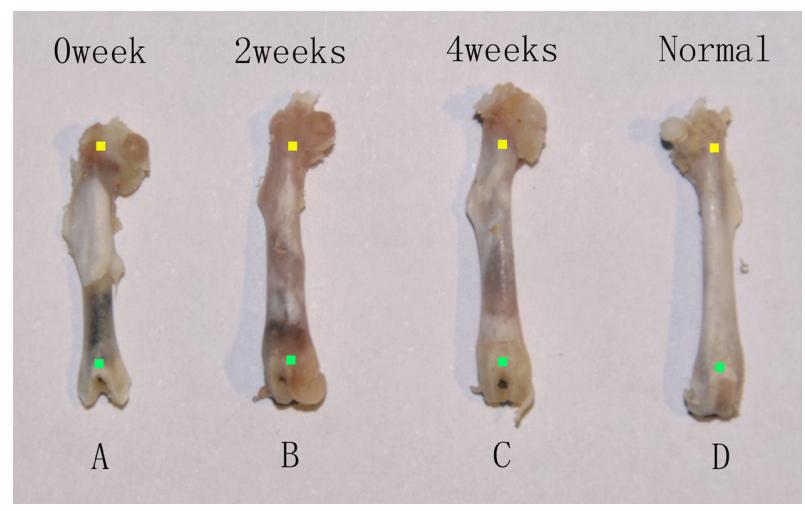

Fig. 4. Gross observation of the injured femur. The yellow squares indicate the proximal femur, and the green squares indicate the distal femur. (A) The marrow cavity of the electrically shocked mice showed hemorrhage, and a large black necrotic area appeared. (B) The area in the bone marrow cavity affected by hemorrhage and necrosis was significantly decreased at 2 weeks. (C) At 4 weeks, the marrow cavity of the electrically shocked mice exhibited better recovery than at 2 weeks previously. (D) A normal femur.

\section{Histopathological observation}

The injury in the distal femur was highly significant, but no injury was observed in the proximal femur. In the distal femur, the cells were disordered and loosely arranged at 0 week. The cellular structure and trabecular bone were evidently damaged. A large number of red blood cells and initially trabecular bone appeared in the injured distal femur after 2 weeks. After 4 weeks, red blood cells disappeared, but large amounts of mature trabecular bone were apparent, amounting to more than that observed 2 weeks previously. (Fig. 5).

The expression of CD34 was observed in the distal femur after 2 weeks, and more apparent expression was detected after 4 weeks. This showed that the blood vessels were evidently damaged in the distal femur, and almost no blood vessels existed at 0 weeks. A large number of new blood capillaries and sinusoids appeared in the injured distal femur after 2 weeks. The capillaries in the injured distal femur disappeared after 4 weeks, and mature blood vessels were scattered throughout the injured area. These results revealed that the injured distal femoral blood vessels were significantly changed (Fig. 6).

\section{Micro-CT angiography analysis}

The right distal femoral blood vessels were damaged after electric shock was induced. By comparison, the vessels remained intact in the injured proximal femur not exposed to electric shock. A large number of new
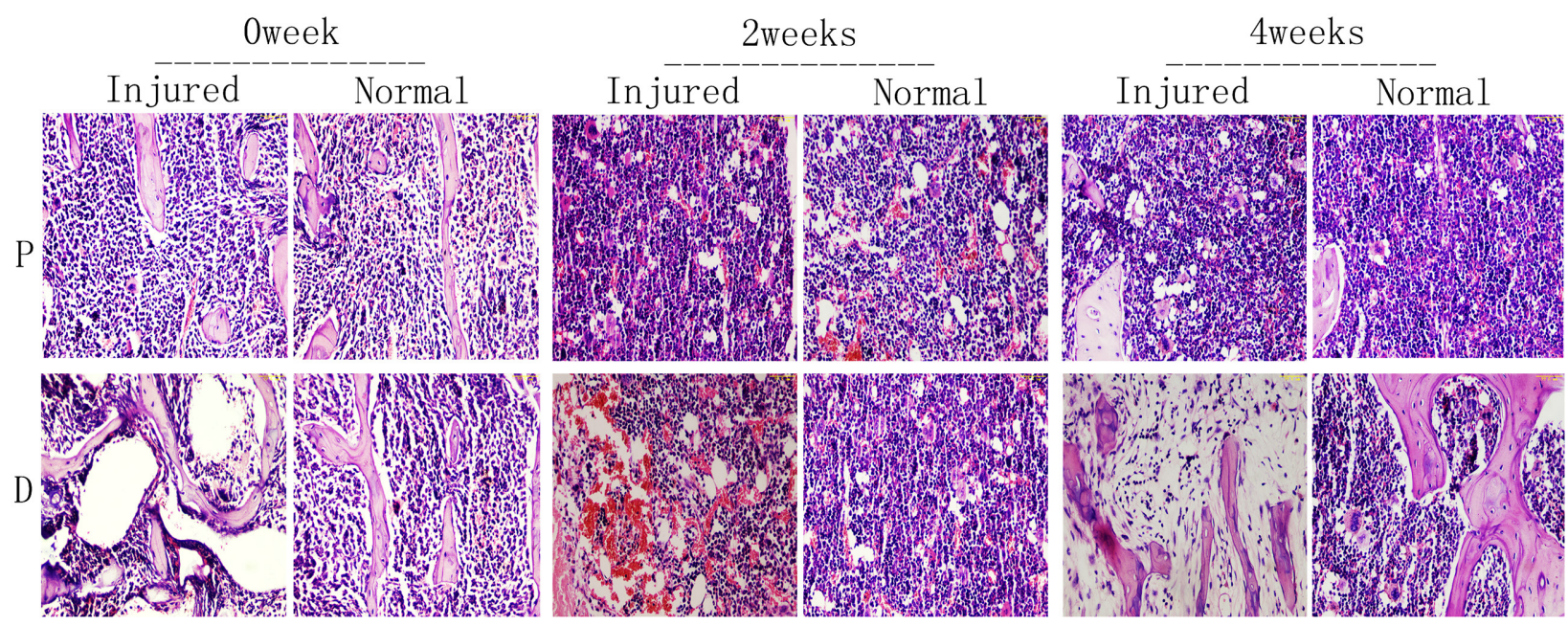

Fig. 5. H\&E staining. Light micrographs of $H \& E(\times 200)$ staining performed on bone marrow microenvironment sections from proximal and distal femora of mice at 0 week, 2 weeks, and 4 weeks after electric shock. P indicates proximal femur, and D indicates distal femur (scale bar: $22.5 \mu \mathrm{m}$.) 

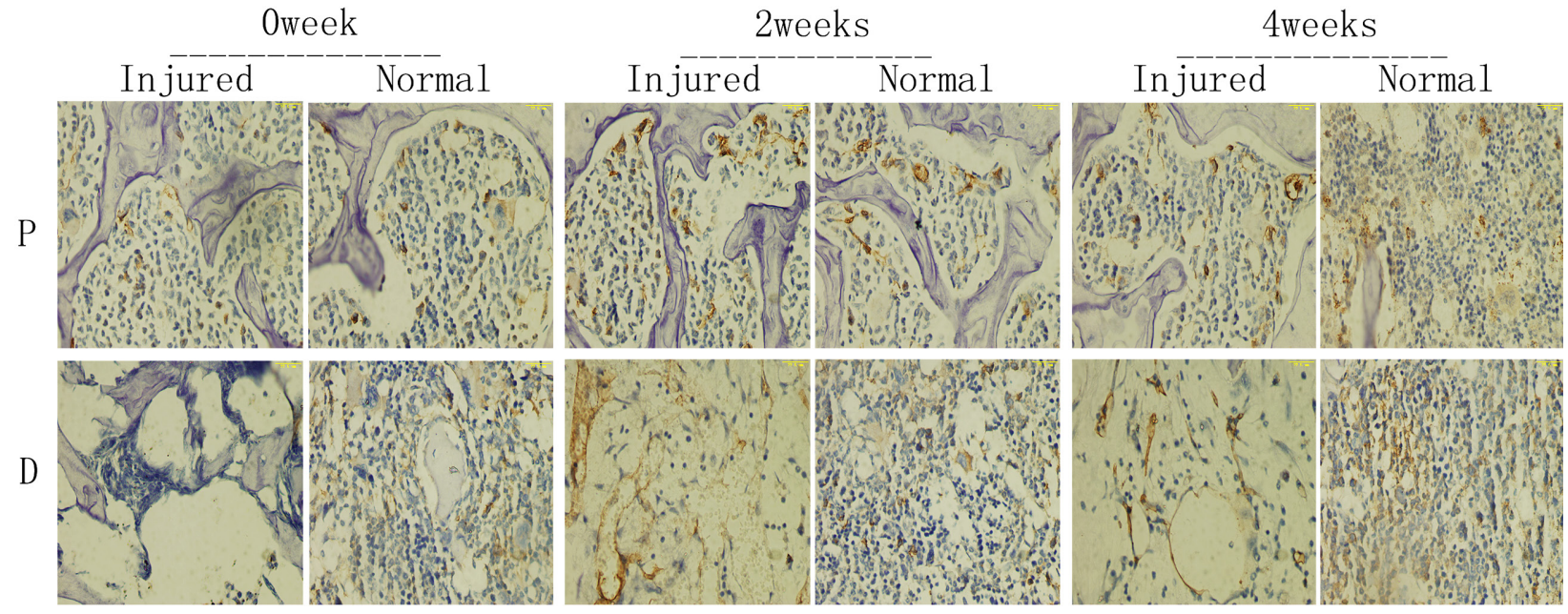

Fig. 6. Immunohistochemistry. Light micrographs of Immunohistochemical staining $(\times 400)$ performed on CD34 expressed in bone marrow microenvironment sections from proximal and distal femora of mice at 0 week, 2 weeks, and 4 weeks after electric shock. P indicates proximal femur, and D indicates distal femur (scale bar: $22.5 \mu \mathrm{m}$.)

A

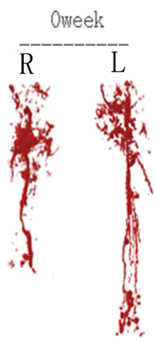

C

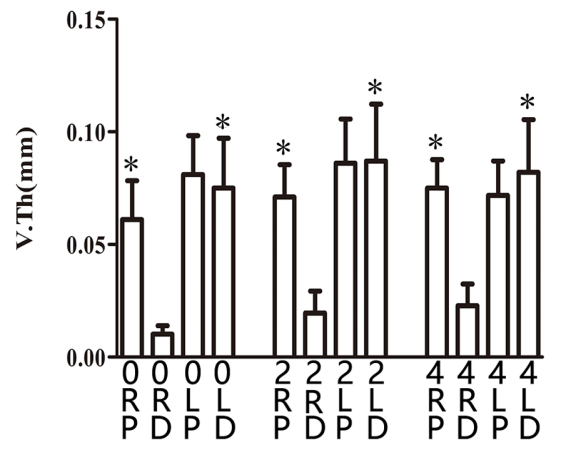

$\mathrm{B}$

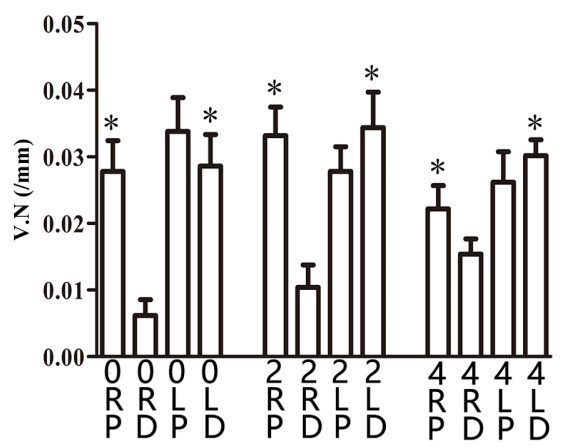

Fig. 7. Micro-CT angiography analysis. (A) Representative 3D micro-CT images of femora from the mice after local electric shock (scale bar: $1 \mathrm{~mm}$ ). (B-D) Quantitative micro-CT angiography analysis. Vascular volume fraction (VV/TV) (B), vascular thickness (V.Th) (C), and vascular number (V.N) (D) were measured. Data represent the mean \pm SEM $\left(n=10,{ }^{*} P<0.05\right)$. Asterisks $(*)$ indicate that comparison with the area of electric shock was meaningful.

blood capillaries and sinusoids appeared in the injured distal femur after 2 weeks. The capillaries in the injured distal femur disappeared after 4 weeks, and mature blood vessels were scattered throughout the injured area (Fig.
7A). Morphometric analysis revealed that the volume, thickness, and number of vessels in the distal femur were lower than those of the control femur (Figs. 7B-D). 


\section{Discussion}

Small animal models have been established to investigate the bone marrow microenvironment. For example, a small animal model of bone marrow microenvironment damage caused by local bone injury has been established by using a small animal radiation research platform (SARRP). (4) This instrument significantly damages the bone marrow microenvironment of mice, but the area of the damage is small. However, the skin, muscle, blood vessel, and bone cortex of the irradiated area exhibit different degrees of injury, which affects the recovery of the bone marrow microenvironment. An SARRP entails high costs, requires complex operations, and harms the health of operators.

In this study, a simple, convenient, accurate, and safe self-made electric shock device was used for the first time to induce stable damage to the bone marrow microenvironment of mice while maintaining a low mortality rate. After 2 and 4 weeks, various changes in the recovery of the bone marrow microenvironment were demonstrated. Thus, the proposed model provided a good technical platform to examine vascular regeneration and segmentation of the bone marrow microenvironment. The bone marrow microenvironment was damaged, while the blood vessels, nerves, muscles, and other tissues surrounding the femur remained uninjured by applying the direct insertion of an iron-nickel-chromium alloy wire into the marrow cavity. Drilling with a $1 \mathrm{ml}$ syringe needle and the low degree of bone cortex damage ensured the integrity of the bone marrow cavity and shortened the recovery period. The wire was inserted into the bone marrow cavity to reduce the voltage and time required for the electric shock and to enable safe operation. In the experimental design, we aimed to damage the bone marrow microenvironment in the distal femur, while that was not observed in the proximal femur. The proposed model provides a suitable experimental platform and a convenient strategy to investigate the recovery of the bone marrow microenvironment for further research of stem cell renewal, differentiation, migration, resting, mobilization, and homing. The materials used to create the proposed electric shock device were inexpensive, safe, and highly stable.

The bone marrow microenvironment injury model designed in this study was limited by the required long duration of electric shock and high electric shock voltage. The range of fluctuation was also large. In a pre- liminary experiment, different metal wires were used to damage the bone marrow microenvironment through heat, but these materials were not optimum for the desired model. The iron-nickel-chromium alloy was one of the few materials that could damage the bone marrow microenvironment of the femur at a lower voltage, and mortality was low in the mice. In future experiments, other metal wires will be tested to shorten the duration of shock and reduce the voltage. In the current experiment, healthy 12 -week-old BALB/c mice with a femur length of $1.7-2.0 \mathrm{~cm}$ were selected, and differences among the mice altered the optimal voltage and time range. Thus, mice with similar sizes should be selected as experimental animals to reduce the range of fluctuation of the optimum shock voltage and time. During the experiment, the femur and console needed to be fully secured vertically for drilling with $1 \mathrm{ml}$ syringe needle because the bone marrow cavity of the mouse femur is fine and extremely irregular. Otherwise, the femur and console would likely be positioned sideways, thus causing a perforation of the cortical bone. In a future study, other insertion methods will be demonstrated to improve the mouse model and establish new methods for the development of bone marrow microenvironment injury models.

\section{Acknowledgments}

This research was supported by grants from the National Natural Science Foundation of China (31271458); the science and technology program of Xinjiang Production and Construction Corps (2014AB047); the Scientific Research Foundation for the Returned Overseas Chinese Scholars, Ministry of Human Resources and Social Security of the People's Republic of China (RSLX201201); and the Shihezi University Youth Science and Technology Research and Development Program, Basis and Application Research Project (20142RKXYQ20).

\section{References}

1. Baskerville, J.R. and McAninch, S.A. 2002. Focal lingual dystonia, urinary incontinence, and sensory deficits secondary to low voltage electrocution: case report and literature review. Emerg. Med. J. 19: 368-371. [Medline] [CrossRef]

2. Battiwalla, M. and Hematti, P. 2009. Mesenchymal stem cells in hematopoietic stem cell transplantation. Cytotherapy 11: 503-515. [Medline] [CrossRef] 
3. Colmone, A., Amorim, M., Pontier, A.L., Wang, S., Jablonski, E., and Sipkins, D.A. 2008. Leukemic cells create bone marrow niches that disrupt the behavior of normal hematopoietic progenitor cells. Science 322: 1861-1865. [Medline] [CrossRef]

4. Cao, X., Wu, X., Frassica, D., Yu, B., Pang, L., Xian, L., Wan, M., Lei, W., Armour, M., Tryggestad, E., Wong, J., Wen, C.Y., Lu, W.W., and Frassica, F.J. 2011. Irradiation induces bone injury by damaging bone marrow microenvironment for stem cells. Proc. Natl. Acad. Sci. USA 108: 1609-1614. [Medline] [CrossRef]

5. Danielsen, L., Karlsmark, T., Thomsen, H.K., Thomsen, J.L., and Balding, L.E. 1991. Diagnosis of electrical skin injuries. A review and a description of a case. Am. J. Forensic Med. Pathol. 12: 222-226. [Medline] [CrossRef]

6. Jorgensen, C. 2010. Mesenchymal stem cells in arthritis: role of bone marrow microenvironment. Arthritis Res. Ther. 12: 135. [Medline] [CrossRef]

7. Jacobsen, H. 1997. Electrically induced deposition of metal on the human skin. Forensic Sci. Int. 90: 85-92. [Medline] [CrossRef]

8. James, T.N., Riddick, L., and Embry, J.H. 1990. Cardiac abnormalities demonstrated postmortem in four cases of accidental electrocution and their potential significance relative to nonfatal electrical injuries of the heart. Am. Heart J. 120: 143-157. [Medline] [CrossRef]

9. Katayama, Y., Battista, M., Kao, W.M., Hidalgo, A., Peired, A.J., Thomas, S.A., and Frenette, P.S. 2006. Signals from the sympathetic nervous system regulate hematopoietic stem cell egress from bone marrow. Cell 124: 407-421. [Medline] [CrossRef]

10. Calvi, L.M. and Link, D.C. 2014. Cellular complexity of the bone marrow hematopoietic stem cell niche. Calcif. Tissue Int. 94: 112-124. [Medline] [CrossRef]

11. Lo Celso, C., Fleming, H.E., Wu, J.W., Zhao, C.X., MiakeLye, S., Fujisaki, J., Côté, D., Rowe, D.W., Lin, C.P., and Scadden, D.T. 2009. Live-animal tracking of individual haematopoietic stem/progenitor cells in their niche. Nature 457: 92-96. [Medline] [CrossRef]

12. Lane, S.W., Scadden, D.T., and Gilliland, D.G. 2009. The leukemic stem cell niche: current concepts and therapeutic opportunities. Blood 114: 1150-1157. [Medline] [CrossRef]

13. Li, W.P., Zhu, M.S., Zhu, Z.X., Guan, J.C., Xu, X.G., LiWP 2006. A series of models of non-thermal high voltage electrical injuries. Burns 32: 986-991. [Medline] [CrossRef]

14. Lee, R.C. 1997. Injury by electrical forces: pathophysiology, manifestations, and therapy. Curr. Probl. Surg. 34: 677-764. [Medline] [CrossRef]

15. Lee, R.C., Zhang, D., and Hannig, J. 2000. Biophysical injury mechanisms in electrical shock trauma. Annu. Rev. Biomed. Eng. 2: 477-509. [Medline] [CrossRef]

16. Méndez-Ferrer, S., Lucas, D., Battista, M., and Frenette, P.S. 2008. Haematopoietic stem cell release is regulated by circadian oscillations. Nature 452: 442-447. [Medline] [CrossRef]

17. Mansour, A., Abou-Ezzi, G., Sitnicka, E., Jacobsen, S.E., Wakkach, A., and Blin-Wakkach, C. 2012. Osteoclasts promote the formation of hematopoietic stem cell niches in the bone marrow. J. Exp. Med. 209: 537-549. [Medline] [Cross-
Ref]

18. Mishra, P.J., Mishra, P.J., Glod, J.W., and Banerjee, D. 2009. Mesenchymal stem cells: flip side of the coin. Cancer Res. 69: 1255-1258. [Medline] [CrossRef]

19. Matsuda, H., Seo, Y., and Takahama, K. 1997. A medicolegal approach to the myocardial changes caused by transthoracic direct current countershock. Nippon Hoigaku Zasshi 51: 11-17. [Medline]

20. Norkus, T., Klebanovas, J., Viksraitis, S., Astrauskas, T., Gelunas, J., Rimkus, R., and Zobakas, A. 1998. Deep electrical burns of the calvarium: early or delayed reconstruction? Burns 24: 569-572. [Medline] [CrossRef]

21. Püschel, K., Brinkmann, B., and Lieske, K. 1985. Ultrastructure alteration of skeletal muscles after electric shock. Am. J. Foresic. Med. Pathol. 6: 296-300.

22. Ramakrishnan, A. and Deeg, H.J. 2009. A novel role for the marrow microenvironment in initiating and sustaining hematopoietic disease. Expert Opin. Biol. Ther. 9: 21-28. [Medline] [CrossRef]

23. Schroeder, T. 2010. Hematopoietic stem cell heterogeneity: subtypes, not unpredictable behavior. Cell Stem Cell 6: 203-207. [Medline] [CrossRef]

24. Stavroulaki, E., Kastrinaki, M.C., Pontikoglou, C., Eliopoulos, D., Damianaki, A., Mavroudi, I., Pyrovolaki, K., Katonis, P., and Papadaki, H.A. 2011. Mesenchymal stem cells contribute to the abnormal bone marrow microenvironment in patients with chronic idiopathic neutropenia by overproduction of transforming growth factor- $\beta 1$. Stem Cells Dev. 20: 1309-1318. [Medline] [CrossRef]

25. Thomsen, H.K., Danielsen, L., Nielsen, O., Aalund, O., Nielsen, K.G., Karlsmark, T., and Genefke, I.K. 1981. Early epidermal changes in heat- and electrically injured pig skin. I. A light microscopic study. Forensic Sci. Int. 17: 133-143. [Medline] [CrossRef]

26. Thomsen, H.K., Danielsen, L., Nielsen, O., Aalund, O., Nielsen, K.G., Karlsmark, T., Genefke, I.K., and Christoffersen, P. 1983. The effect of direct current, sodium hydroxide and hydrochloric acid on pig epidermis. A light microscopic and electron microscopic study. Acta Pathol. Microbiol. Immunol. Scand. [A] 91: 307-316. [Medline]

27. Takamiya, M., Saigusa, K., Nakayashiki, N., and Aoki, Y. 2001. A histological study on the mechanism of epidermal nuclear elongation in electrical and burn injuries. Int. J. Legal Med. 115: 152-157. [Medline] [CrossRef]

28. Thomsen, H.K., Danielsen, L., Nielsen, O., Aalund, O., Nielsen, K.G., Karlsmark, T., and Genefke, I.K. 1981. Early epidermal changes in heat- and electrically injured pig skin. II. An electron microscopic study. Forensic Sci. Int. 17: 145152. [Medline] [CrossRef]

29. Torre, C. and Varetto, L. 1985. The ultrastructure of the electric burn in man: a transmission electron microscopyscanning electron microscopy study. J. Forensic Sci. 30: 448-455. [Medline] [CrossRef]

30. Xie, Y., Yin, T., Wiegraebe, W., He, X.C., Miller, D., Stark, D., Perko, K., Alexander, R., Schwartz, J., Grindley, J.C., Park, J., Haug, J.S., Wunderlich, J.P., Li, H., Zhang, S., Johnson, T., Feldman, R.A., and Li, L. 2009. Detection of functional haematopoietic stem cell niche using real-time imaging. Nature 457: 97-101. [Medline] [CrossRef] 